\title{
A survey on the clinical spectrum of Aspergillus infections in Isfahan, Iran, during 2010-2018
}

Mostafa Chadeganipour

Isfahan University of Medical Sciences

Rasoul Mohammadi ( $\nabla$ dr.rasoul_mohammadi@yahoo.com )

Isfahan University of Medical Sciences https://orcid.org/0000-0002-8220-4511

Research article

Keywords: Aspergillus infections, Etiologic agent, Retrospective study, Iran

Posted Date: January 21st, 2020

DOI: https://doi.org/10.21203/rs.2.20905/v2

License: (9) This work is licensed under a Creative Commons Attribution 4.0 International License.

Read Full License 
The authors have withdrawn this preprint from Research Square 